\title{
Evidence of a joint control of chiasma formation in spermatocytes and oocytes of a grasshopper
}

\section{J. L. Santos and \\ M. I. Cano}

Departamento de Genética, Facultad de Biología, Universidad Complutense, 28040 Madrid, Spain.

Frequency of chiasmata was studied in male and female full-sibs belonging to nine genetically different families from the grasshopper Eyprepocnemis plorans. Mean cell chiasma frequency was always higher in spermatocytes than in oocytes. Furthermore, a positive correlation between both parameters in the families studied was observed. It is concluded that chiasma formation in both sexes is under a single genetic controlling system, chiasma sex differences being a reflection of a differential response of such control to the differing conditions of spermatocytes and oocytes.

\section{INTRODUCTION}

Differences in chiasma frequency between sexes seem to be a widespread phenomenon in animals since they have been observed in species from different taxonomic groups such as planarians (Pastor and Callan, 1952; Jones and Croft, 1989), grasshoppers (Cano and Santos, 1990 and references therein), urodele amphibians (Callan and Perry, 1977), marsupials (Bennett et al., 1986; Hayman et al., 1988) and eutherian mammals (Dunn and Bennett, 1967; Andersson and Sandberg, 1984).

Information about this point is more scarce in plants. However sex differences in chiasma frequency have also been established in several plants, including Lilium and Fritillaria (Fogwill, 1958); Tulbaghia (Vosa, 1972); maize (Rhoades, 1978); some species of Allium (Gohil and Kaul, 1980); and Pinus radiata (Moran et al., 1983).

A more fundamental question which emerges from these findings, is whether such differences are indicative of separate meiotic controls in the two sexes or, on the contrary, they represent the response of a joint control to differing conditions in each sex (see Davies and Jones, 1974). In this paper we study this topic by comparing male and female chiasma frequency in full sibs belonging to nine genetically different families from the grasshopper Eyprepocnemis plorans.

\section{MATERIAL AND METHODS}

Gravid Eyprepocnemis plorans females were collected in different natural populations and maintained in the laboratory in order to obtain pods. After 30 days at room temperature, pods were kept for at least 45 more days at $4^{\circ} \mathrm{C}$ and then incubated at $33^{\circ} \mathrm{C}$ until eclosion of the eggs. The individuals obtained from each female pod (a "family") were considered to be full-sibs since they correspond to the insemination of a single male (López, 1987). Each family was maintained separately in 501 cages. Fifteen days after the appearance of adult males, testes were fixed in acetic-alcohol $1: 3$. Squash preparations of the fixed material were stained with acetic-orcein.

Squash preparations of oocyte first metaphases were made using the method of Perry and Jones (1974) as modified by Henriques-Gil et al., (1986). To ensure comparability, a chiasma scoring was carried out on first metaphase stages in both oocytes and spermatocytes under the assumption that chiasma terminalisation does not exist in this species (Santos, unpublished results). Ten sper- 
matocytes were scored per male insect and between six and ten oocytes per females. The number of individuals analysed in the nine families obtained is shown in table 1 .

Table 1 A summary of mean chiasma frequencies $(\bar{x})$ in males and females of nine families from Eyprepocnemis plorans; $n=$ number of individuals examined

\begin{tabular}{|c|c|c|c|c|}
\hline \multirow[b]{2}{*}{ Family } & \multicolumn{2}{|l|}{ Females } & \multicolumn{2}{|l|}{ Males } \\
\hline & $\hat{x}$ & $n$ & $\bar{x}$ & $n$ \\
\hline DA-D & $12 \cdot 23 \pm 0.05$ & 5 & $14 \cdot 00 \pm 0.42$ & 3 \\
\hline DA-L & $12 \cdot 82 \pm 0 \cdot 26$ & 4 & $13.77 \pm 0.06$ & 4 \\
\hline DA-H & $12 \cdot 93 \pm 0 \cdot 14$ & 6 & $13 \cdot 65 \pm 0 \cdot 26$ & 6 \\
\hline DA-M & $12.93 \pm 0.14$ & 9 & $13 \cdot 86 \pm 0 \cdot 20$ & 9 \\
\hline FG-A & $12 \cdot 93 \pm 0 \cdot 11$ & 4 & $13.92 \pm 0.28$ & 4 \\
\hline SA-B & $13 \cdot 50 \pm 0 \cdot 12$ & 5 & $14 \cdot 08 \pm 0 \cdot 24$ & 5 \\
\hline SC-C & $13 \cdot 72 \pm 0 \cdot 40$ & 4 & $14 \cdot 65 \pm 0.28$ & 4 \\
\hline SA-U & $14 \cdot 16 \pm 0 \cdot 35$ & 5 & $14 \cdot 27 \pm 0 \cdot 32$ & 3 \\
\hline JE-B & $14 \cdot 35 \pm 0 \cdot 31$ & 4 & $15.62 \pm 0.66$ & 4 \\
\hline
\end{tabular}

\section{RESULTS}

Table 1 gives the mean cell chiasma frequencies of male and female grasshoppers from the nine families studied. They range from $12 \cdot 23$ to $14 \cdot 35$ chiasmata per cell in females, and from 13.65 to 15.62 chiasmata per cell in males. Therefore a similar range of variation, about two chiasmata per cell is observed in both sexes. It should be noted that female means are based on 12 bivalents, including the $X$ chromosome pair, while male means are based on only 11 autosomal bivalents, the single male $\mathrm{X}$ chromosome forming an univalent in the spermatocytes.

Chiasma number per cell was subjected to a mixed model of analysis of variance considering sex, family and individuals as sources of variation. The analysis was adjusted for unequal numbers of individuals per family and cells per individual and the results are shown in table 2 . There was a highly significant difference between sexes in their chiasma frequency in agreement with the data

Table 2 Analysis of variance of chiasma frequencies in males and females from nine families of $E$. plorans

\begin{tabular}{lrrrl}
\hline Source & df & \multicolumn{1}{l}{ SS } & \multicolumn{1}{l}{ MS } & \multicolumn{1}{l}{$F$} \\
\hline Families & 8 & 263.688 & 32.961 & $10.45^{*}$ \\
Sexes & 1 & $170 \cdot 291$ & 170.291 & $54.00^{*}$ \\
Families $\times$ Sexes & 8 & 32.867 & $4 \cdot 108$ & $1.30 \mathrm{~ns}$ \\
Individuals & 70 & $220 \cdot 729$ & 3.153 & $5.13^{*}$ \\
Error & 746 & $458 \cdot 230$ & 0.614 & \\
\hline
\end{tabular}

*Significant at 5 per cent level. reported by Cano et al. (1987). Furthermore, the effects of family and individuals were both highly significant. Therefore, it can be concluded that sex differences in chiasma frequency, are at least in part, genotype dependent.

Fig. 1 shows the male mean chiasma frequencies plotted against the female values for the nine families analyzed. A clear significant positive correlation between both parameters is observed $(r=$ $0.762, t=3.11, \mathrm{df}=7, P<0.01)$. On the other hand, chiasma differences between sexes within each family do not seem to be correlated either to male $(r=0.176, t=0.472, \mathrm{df}=7, P>0.5)$, or female $(r=0.503, t=1.542, \mathrm{df}=7,0.2>P>0.1)$ mean chiasma frequencies.

\section{DISCUSSION}

The analysis of meiosis in male and female full-sibs of nine genetically different families has allowed us to assess the influence of the genotype in relation to chiasma control in both sexes of the grasshopper $E$. plorans. The positive correlation found between male and female chiasma frequencies for the families studied can be considered as a good evidence for the existence of a joint control on chiasma formation in both sexes (Davies and Jones, 1974). If a joint control exists, chiasma sex differences could be a reflection of a differential response of such control to the differing conditions of spermatocytes and oocytes.

Information about this subject in other organisms is scarce, as far as we know there are only a few reports with analogous findings to those reported here, thus Pastor and Callan (1952) and Jones and Croft (1989) have reported in the hermaphroditic planarian Dendrocoelum lacteum a positive correlation between chiasma frequencies of oocytes and spermatocytes in the same individuals. Likewise, Davies and Jones (1974) found considerable differences for mean chiasma frequencies in pollen mother cells and embryo-sac mother cells of five distinct inbred lines although very little variation was seen between both types of cells belonging to the same lines.

A different situation to those mentioned above is provided by Drosophila melanogaster where most meiotic mutants are sex specific and act at the first meiotic division. On the contrary, the mutants that increase nondisjunction at the second meiotic division affect chromosome behaviour in both sexes, suggesting that this division is under common control in both sexes. However, as Baker et al. (1976) have stated the meiotic loci identified 


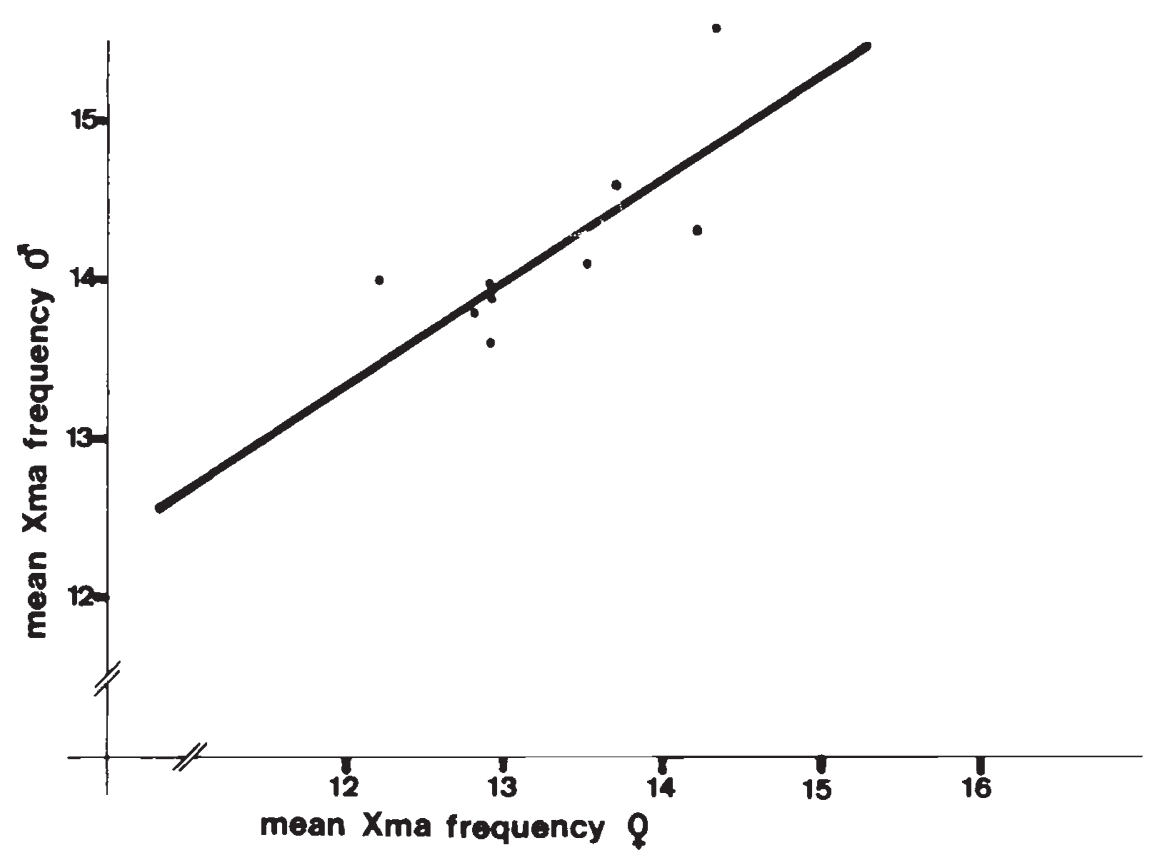

Figure 1 Spermatocyte $(\delta)$ mean chiasma frequencies plotted against oocyte $(q)$ mean chiasma (Xma) frequencies for the nine families analysed of $E$. plorans.

to date in this species represent the subset of such loci that is dispensable for viability and functional gamete formation. Therefore the apparent completely separate genetic control of the first meiotic division in the two sexes may be a consequence of the types of mutant screens that have been employed.

In summary, evidences indicating that chiasma formation in male and female meiocytes is governed and regulated by a single controlling system of genes come from species as different as Dendrocoelum lacteum where females have 66 per cent more chiasmata than males (Jones and Croft, 1989), rye in which both sexes present similar chiasma frequencies and E. plorans (this paper) where males display the higher recombination frequencies. However, simultaneous occurrence of a general controlling system involved in the cellular control of recombination in both sexes and some sex-specific genes regulating particular features of meiotic process in male and female meiocytes cannot absolutely be discarded.

Acknowledgements We are specially grateful to Dr A. Gallego of the Genetics Department, Universidad Complutense, for her help with the statistical analysis, and to Dr Gareth Jones, University of Birmingham, for critical discussion of this paper.

\section{REFERENCES}

ANDERSSON, L. AND SANDBER, K. (1984) Genetic linkage in the horse. II. Distribution of male recombination estimates and the influence of age, breed and sex on recombination frequency. Genetics, 106, 109-122.

BAKER, B. S., CARPENTER, A. T. C., ESPOSITO, M. S., ESPOSITO, R. G. AND SANDLER, L. (1976) The genetic control of meiosis. A. Rev. Genet., 10, 53-134.

BENNETT, J. H., HAYMAN, D. L. AND HOPE, R. M. (1986) Novel sex differences in linkage values and meiotic chromosome behaviour in a marsupial. Nature, 323, 59-60.

CALLAN, H. G. AND PERRY, P. E. (1977) Recombination in male and female meiocytes contrasted. Phil. Trans. R. Soc. Lond. $B, 277,237-243$.

CANO, M. I., JONES, G. H. AND SANTOS, J. L. (1987) Sex differences in chiasma frequency and distribution in natural populations of Eyprepocnemis plorans containing B chromosomes. Heredity, 59, 237-243.

CANO, M. I. AND SANTOS, J. L. (1990) Chiasma frequencies and distributions in Gomphocerine grasshoppers: a comparative study between sexes. Heredity, 64, 17-23.

DAVIES, E. D. G. AND JONES, G. H. (1974) Chiasma variation and control in pollen mother cells and embryo-sac mother cells of rye. Genet. Res., 23, 185-190.

DUNN, L. C. AND BENNETT, D. (1967) Sex differences in recombination of linked genes in animals. Genet. Res., 9, 211-220.

FOGWILL, M. (1958) Differences in crossing-over and chromosome size in the sex cells of Lilium and Fritillaria. Chromosoma, 2, 493-504.

GOHIL, R. N. AND KAUL, R. (1980) Studies on males and females meiosis in Indian Allium. I. Four diploid species. Chromosoma, 77, 123-127. 
HAYMAN, D. L., MOORE, H. D. M. AND EVANS, E. P. (1988) Further evidence of novel sex differences in chiasma distribution in marsupials. Heredity, 61, 455-458.

HENRIQUES-GIL, N., JONES, G. H., CANO, M. I., ARANA, P. AND SANTOS, J. L. (1980) Female meiosis during oocyte maturation in Eyprepocnemis plorans (Orthoptera, Acrididae). Can. J. Genet. Cytol., 28, 84-87.

JONES, G. H. AND CROFT, J. A. (1989) Chromosome pairing and chiasma formation in spermatocytes and oocytes of Dendrocoelum lacteum (Turbellaria, Tricladida); a cytogenetical and ultrastructural study. Heredity, 63, 97-106.

LOPEZ LEON, M. D. (1987) Estudio de la transmisión de dos tipos de heterocromatina extra en dos especies de saltamontes. Tesina de licenciature, Universidad de Granada, Spain.
MORAN, G. F., BELL, J. C. AND HILlikER, A. J. (1983) Greater meiotic recombination in male vs. female gametes in Pinus radiata. J. Hered., 74, 62.

PASTOR, J. B. AND CALLAN, H. G. (1952) Chiasma formation in spermatocytes and oocytes of the turbellarian Dendrocoelum lacteum. J. Genet., 50, 449-454.

PERRY, P. E. AND JONES, G. H. (1974) Male and female meiosis in grasshoppers. I. Stetophyma grossum. Chromosoma, 47, 227-236.

RHOADES, M. M. (1978) Genetic effects of heterochromatin in maize. In Waiden, D. B. (ed.) Maize Breeding and Genetics, pp. 641-671.

vosA, C. G. (1972) Two track heredity: differentiation of male and female meiosis in Tulbaghia. Caryologia, 25, 275-281. 